\title{
AVALIAÇÃO DA DISPERSÃO ATMOSFÉRICA DE COMPOSTOS ODORANTES EMITIDOS NA INDÚSTRIA PAPELEIRA
}

Waldir Nagel Schirmer* ${ }^{1}$, Tiago José Belli ${ }^{2}$, Mauricy Kawano ${ }^{3}$, Júlio César Batista Nogueira ${ }^{4}$, Rafaelo Balbinot $^{5}$

1 - Curso de Eng. Ambiental da Universidade Estadual do Centro-oeste, Irati (PR).

2- Engenharia Ambiental pela Universidade Estadual do CentroOeste, Irati (PR).

3 - SENAI CESTAM, Curitiba (PR).

4 - Klabin S.A.., Telêmaco Borba (PR).

5 - Curso de Eng. Ambiental da Universidade Estadual do Centro-Oeste, Irati (PR).

*E-mail:wanasch@yahoo.com.br

Recebido em 12 de dezembro de 2008 Aceito em 09 de janeiro de 2009

\section{RESUMO}

O caráter odorante de compostos reduzidos de enxofre (TRS), tipicamente emitidos na indústria papeleira, tem gerado grande interesse por parte dessas indústrias em predizer a qualidade do ar nas proximidades de suas fontes emissoras. Desse modo, o presente trabalho tem por objetivo avaliar o impacto na atmosfera resultante das emissões de TRS de uma fabricante de papel e celulose de grande porte, por meio da modelagem dos compostos gasosos emitidos a partir de duas fontes pontuais (tomadas como as maiores contribuidoras: caldeira de recuperação e tanque de dissolução). Para tanto, foi utilizado o "software" AID (Avaliação Instantânea de Dispersão) baseado no modelo de Gauss para determinação das concentrações (no ar) resultantes dessas emissões. Nessa determinação, foram abordados os principais parâmetros meteorológicos (dos últimos 3 anos) e cinéticos de emissão necessários à modelagem. A máxima concentração de TRS obtida após a modelagem foi de 3,84 ppb (somatório das duas fontes avaliadas), ficando bem abaixo dos limites de percepção odorífera (LPO) recomendado por órgãos internacionais (o Brasil não possui leis específicas para esse caso). Como os limites de toxicidade quase sempre estão bem acima dos LPO, é seguro afirmar que, no caso avaliado, a concentração máxima estimada não apresenta riscos de toxicidade à população exposta, uma vez, pelo valor obtido, nem o odor pode ser percebido.

Palavras-chave: Compostos reduzidos de enxofre; TRS; Dispersão atmosférica; Odor; Papel.

\section{Introdução}

Os odores, de maneira geral, sempre fazem parte de uma situação ou processo, provocando as mais diversas reações, tanto em uma única pessoa quanto em toda uma população a eles exposta. O maior problema enfrentado, quando se tenta oferecer solução para as reclamações de odor feitas por uma comunidade, é a falta de padrões adequados para orientar as autoridades e administradores ambientais das empresas emissoras de tais poluentes em relação às fontes da indústria e/ou do empreendimento responsável pela emissão do odor.

Entre todos os tipos de poluição ambiental, os maus odores estão entre os mais difíceis de regular, isto porque um cheiro desagradável é considerado algo subjetivo e, portanto, legalmente indefinível. Com base neste princípio, as autoridades ficam impedidas de autuar, a não ser que os maus odores causem, simultaneamente, outro tipo de poluição reconhecida por lei. Por isso são poucos os países onde há legislação para esta forma de poluição [1].

As operações envolvendo a produção de papel e celulose sempre estiveram associadas à emissão de várias substâncias na atmosfera, muitas delas de caráter odorante. Durante estas operações, as emissões de gases e vapores são provenientes de juntas de válvulas, bombas, chaminés, tanques e canais a céu aberto, estações de tratamento de efluentes e demais etapas do processo de produção do papel. Dos poluentes lançados na atmosfera por industrias de papel e celulose, ocupam posição de destaque os compostos reduzidos de enxofre (TRS - do inglês total reduced sulfur), todos de caráter fortemente odorante. Oliveira [2] cita o sulfeto de hidrogênio $\left(\mathrm{H}_{2} \mathrm{~S}\right)$, o metil mercaptana $\left(\mathrm{CH}_{3} \mathrm{SH}\right)$ e o sulfeto dimetila $\left(\mathrm{CH}_{3} \mathrm{SCH}_{3}\right)$ como os TRS de maior importância dentre o range de gases odorantes presentes nas emissões destas indústrias. $\mathrm{O}$ sulfeto de hidrogênio $\left(\mathrm{H}_{2} \mathrm{~S}\right)$, produto da redução do sulfato, é o odorante mais comumente associado a este processo, com forte correlação entre a emissão deste gás e a concentração de odores.

Verifica-se, assim, um interesse cada vez maior por parte das empresas emissoras de gases odorantes em predizer a qualidade do ar nas proximidades de suas fontes emissoras, visando, com isso, avaliar o impacto de seus efluentes gasosos junto às comunidades receptoras. Uma das formas mais utilizadas nessa predição é a utilização da modelagem matemática, uma ferramenta que, neste caso, estima o comportamento dos poluentes gasosos lançados à atmosfera. Assim, baseando-se em critérios como fatores meteorológicos, cinética dos gases, geometria da chaminé e características do relevo próximo ao ponto avaliado, pode-se determinar com bastante segurança o comportamento da dispersão da pluma contaminante e, conseqüentemente, o seu impacto sobre o receptor.

Kawano [3] comenta que o transporte e diluição dos poluentes dependem, sobretudo, de fenômenos meteorológicos locais. Almeida [4] indica a velocidade e a direção dos ventos, a turbulência e a estabilidade 
atmosférica como fenômenos meteorológicos importantes para o transporte e diluição de poluentes atmosféricos numa escala local.

A avaliação das condições de estabilidade atmosférica nem sempre é fácil de ser feita. Alvares Jr, Lacava e Fernandes [5] descrevem que pesquisadores como Pasquill e Turner, baseados em informações de hora do dia, velocidade do vento em superfície, insolação e cobertura de nuvens, propuseram a distribuição das condições de estabilidade da atmosfera em classes, conforme relacionado em [6], citado por [3], o qual varia de extremamente instável (classe A) até estável (classe F) (correlação de estabilidade atmosférica segundo Pasquill-Gifford).

Para Braga [7], a modelagem matemática do transporte dos poluentes baseia-se, conceitualmente, em um simples exercício de contabilidade, onde se avaliam as quantidades que entram e que saem de uma determinada região fixa no espaço, tendo as condições meteorológicas papel preponderante nesse exercício. Kawano [3] comenta que a modelagem dos poluentes dá idéia do grau de exposição da população sob influência (receptores), como resultado final do processo de emissão e as interações dos poluentes na atmosfera (fonte emissora - atmosfera receptor). Ainda segundo este autor, a resultante deste sistema define o nível de qualidade do ar que, por sua vez, desencadeia os efeitos adversos dos poluentes sobre os receptores.

A modelagem vem ganhando força junto às práticas de monitoramento da qualidade do ar por apresentar vantagens em relação a outras ferramentas, como: conseguir estimar as mais altas concentrações de poluentes para as piores condições meteorológicas; prever níveis de concentrações tóxicos de determinados poluentes que não conseguiriam ser detectados por instrumentos analíticos convencionais (abaixo dos limites de detecção) ([8] citado por [3]). Dessa forma, a modelagem matemática do transporte dos poluentes gasosos emerge como importante ferramenta para planejar e gerir de maneira mais racional as fontes poluidoras.

Desse modo, o presente trabalho tem por objetivo avaliar o impacto na atmosfera resultante das emissões de Compostos Reduzidos de Enxofre (TRS) de uma fabricante de papel e celulose, localizada no município de Telêmaco Borba, Estado do Paraná, por meio da modelagem dos compostos gasosos. O trabalho abrange duas das principais fontes emissoras de TRS (chaminés), representativas sobre as demais fontes pontuais da empresa, e faz uso de modelo matemático implementado a um "software" especificamente desenvolvido para fontes pontuais.

\section{Materiais e Métodos}

Para simular a concentração dos Compostos Reduzidos de Enxofre (TRS) emitidos a partir de duas fontes pontuais e aferir os impactos sobre a qualidade do ar na área de influência da fábrica, foi utilizado o modelo matemático de dispersão AID (Avaliação Instantânea de Dispersão) desenvolvido por Kawano [3].
Paralelamente, aplicou-se o modelo de Gauss em cada fonte para verificação dos valores absolutos da concentração cuja faixa foi estimada no modelo AID.

Foram abordadas no trabalho as condições climáticas da área de influência do complexo de indústrias, baseadas num histórico meteorológico entre o período de 2003 a 2005, bem como visitas técnicas exploratórias de reconhecimento integrado.

Os parâmetros de emissões adotados para o cálculo das concentrações de TRS foram obtidos através de campanhas reais de amostragens nas chaminés da empresa como parte do programa permanente de controle das fontes fixas de emissões atmosféricas da fábrica.

Para avaliação do impacto ambiental da emissão de poluentes foram utilizadas as piores condições meteorológicas em termos de estabilidade atmosférica à dispersão dos poluentes, de modo a superestimar os valores obtidos. Por fim, as concentrações encontradas foram comparadas às legislações concernentes.

\section{Caracterização das fontes emissoras}

Dentre as diversas fontes de emissões atmosféricas da fábrica de papel e celulose avaliada, a caldeira de recuperação e o tanque de dissolução merecem destaque, sobretudo quanto à emissão de TRS. Estas duas unidades, que compõem o sistema de recuperação na planta industrial, têm por finalidade reduzir as perdas de produtos químicos, diminuir o consumo de energia reduzindo, desse modo, o custo da produção [3]. Chama atenção também o beneficio ambiental deste sistema, pois evitam-se os impactos que estes químicos (ao serem lançados diretamente) causariam no meio ambiente se não fossem devidamente recuperados.

Neste trabalho, foram enfatizadas as emissões pontuais dessas duas unidades: caldeira de recuperação e tanque de dissolução. Os gases emanados da caldeira e do tanque de dissolução compreendem, principalmente, o sulfeto de hidrogênio $\left(\mathrm{H}_{2} \mathrm{~S}\right)$, a metil mercaptana $\left(\mathrm{CH}_{3} \mathrm{SH}\right)$, a dimetil mercaptana $\left(\mathrm{CH}_{3} \mathrm{SCH}_{3}\right)$ e o dimetil dissulfeto $\left(\mathrm{CH}_{3} \mathrm{SSCH}_{3}\right)$.

Alguns parâmetros das fontes emissoras também podem influir sobremaneira na dispersão de poluentes atmosféricos. Braga [7] cita a altura e o diâmetro da chaminé, por exemplo, como aspectos determinantes nesse processo, bem como a temperatura dos gases e a posição espacial que o despejo ocupa. A Tabela 1 apresenta alguns parâmetros das duas fontes avaliadas.

\section{Caracterização climática da região de estudo}

Neste trabalho, foram utilizados os dados meteorológicos de uma estação localizada dentro da área de estudo, visando assim gerar um cenário onde o processo de dispersão fosse o mais próximo possível do real. Os dados referem-se à temperatura, pressão atmosférica, vento (direção e velocidade) e estabilidade atmosférica. O período de dados disponíveis para o estudo é de 2003 a 2005. A análise de cada parâmetro teve por objetivo identificar o período mais crítico para dispersão de poluentes na região ao longo do ano. A seguir será apresentada uma breve descrição de cada parâmetro meteorológico, reunidos em forma de tabela e gráfico. 
Tabela 1 - Parâmetros-padrões de emissão e geométricos das duas fontes da fábrica estudada.

\begin{tabular}{ccccccc}
\hline Fontes & \multirow{2}{*}{$\begin{array}{c}\text { Taxas de Emissão } \\
\text { TRS }\left(\mathbf{g . s}^{-\mathbf{1}}\right)\end{array}$} & \multicolumn{4}{c}{ Parâmetros da Fonte } \\
\cline { 4 - 7 } Chaminés & 0,426 & $\mathrm{Q}\left(\mathrm{m}^{3} / \mathrm{s}\right)$ & $\mathrm{H}(\mathrm{m})$ & $\mathrm{D}(\mathrm{m})$ & $\mathrm{v}_{\mathrm{S}}(\mathrm{m} / \mathrm{s})$ & $\mathrm{T}(\mathrm{K})$ \\
\hline Caldeira de recuperação & 0,323 & 177,69 & 64,11 & 2,9 & 26,9 & 458,9 \\
Tanque de dissolução & & 14,71 & 59,2 & 1,0 & 15,5 & 376,5 \\
\hline
\end{tabular}

$\begin{array}{cc}\text { H: altura geométrica da chaminé } & \mathrm{v}_{\mathrm{s}} \text { : velocidade do gás na saída da chaminé } \\ \text { Q: vazão volumétrica do gás } & \text { T: temperatura do gás na chaminé }\end{array}$

D: diâmetro da chaminé

\section{- Vento}

Os dados referentes à direção do vento foram obtidos a partir de uma estação meteorológica onde eram feitas medições em oito direções primárias do vento. A freqüência de cada direção foi contabilizada em número de horas por dia associada a cada direção. Os resultados apontaram que a direção predominante do vento é de Noroeste (NW) com $22,91 \%$ na faixa de velocidade 0,51 a $1,8 \mathrm{~m} . \mathrm{s}^{-1}$; a segunda direção predominante é a de Sudoeste (SW) com 17,74\% na faixa de velocidade entre 0,51 e 1,8 $\mathrm{m} . \mathrm{s}^{-1}$. Essas direções ocorreram com maior freqüência durante todo o período avaliado. Portanto, a velocidade do vento associado às essas direções oscila entre fraca $(77,26 \%)$ e moderada (2,69\%) o que, de acordo com SECA [9], é um indicador de condição pouco favorável à dispersão de poluentes na área de influência do empreendimento.

\section{- Temperatura}

A Tabela 2 apresenta a distribuição da temperatura média mensal, da máxima média e a mínima média, referente aos anos de 2003 a 2005 . Verifica-se que a partir do mês de abril ocorre uma queda das temperaturas atingindo os menores valores entre os meses de maio e julho, sendo este último o mês mais frio, com uma média de $15,56{ }^{\circ} \mathrm{C}$. Essa temperatura "baixa" coincide com a maior pressão atmosférica, onde esses parâmetros indicam o domínio de uma atmosfera mais densa e menos favorável à dispersão de poluentes. Essa condição, segundo SECA [9], contribui para uma maior propagação e difusão de odor na atmosfera devido à predominância das condições estáveis ou turbulência fraca. Após a passagem do inverno, a temperatura entra em processo de elevação, instabilizando a atmosfera e tornando-a mais favorável à dispersão de poluentes.

\section{- Estabilidade atmosférica}

Em trabalho desenvolvido por SECA [9], utilizando critérios estabelecidos por Pasquill-Turner, desenvolveu-se a classificação da estabilidade atmosférica para região onde está inserida a planta avaliada. Este estudo verificou que predominância da estabilidade atmosférica recaiu sobre a categoria D caracterizando, portanto, estabilidade neutra.

\section{Modelo de dispersão atmosférica utilizado}

Os modelos de qualidade do ar, ou modelos de dispersão, como já comentado, são ferramentas matemáticas que, com base em dados como emissão, meteorologia, topografia, etc., estimam as concentrações dos poluentes na atmosfera, tornando possível avaliar o impacto de fontes ou grupo de fontes na qualidade do ar para uma dada região. Existem diversas classificações para os modelos de qualidade do ar. Uma delas, baseada no algoritmo de cálculo para a avaliação da dispersão atmosférica, divide os modelos em quatro categorias, a saber: Gaussianos; Numéricos; Estatísticos e Físicos [6].

Os modelos gaussianos são os de uso mais freqüente nos estudos de impacto de fontes de poluição do ar, sobretudo no caso de fontes de poluentes primários (emitidos diretamente na atmosfera). As equações que descrevem a aproximação gaussiana, de acordo com Boçon [10], são soluções analíticas da equação de conservação de uma espécie química sob certas hipóteses simplificativas, as quais reduzem a equação diferencial a uma forma mais simples e que possui solução analítica. Segundo Kawano [3], a equação gaussiana (1), descrita em Turner [6], é utilizada para uma situação onde a emissão contínua é de uma chaminé e o ponto de medição, ou avaliação, está a uma distância $\mathrm{x}$, deslocado horizontalmente do centro da pluma a uma distância y e a uma altura definida $\mathrm{z}$.

Tabela 2 - Temperatura média, máxima média e mínima média de 2003 a 2005.

\begin{tabular}{|c|c|c|c|c|c|c|c|c|c|c|c|c|c|c|}
\hline & & \multicolumn{13}{|c|}{ Mês - 2003 a 2005} \\
\hline & & Jan & Fev & Mar & Abr & Mai & Jun & Jul & Ago & Set & Out & Nov & Dez & Média \\
\hline \multirow{3}{*}{ 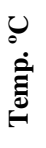 } & Tmédia & 22.80 & 22.63 & 22.00 & 20.53 & 16.43 & 17.00 & 15.56 & 17.33 & 18.83 & 19.93 & 21.03 & 21.93 & 19.62 \\
\hline & Tmáxima & 25.90 & 24.90 & 24.50 & 22.90 & 18.70 & 18.90 & 17.50 & 19.90 & 21.40 & 22.10 & 23.40 & 24.10 & 21.90 \\
\hline & Tmínima & 18.40 & 17.40 & 16.80 & 15.90 & 11.80 & 12.80 & 10.90 & 11.20 & 13.40 & 14.90 & 15.60 & 17.20 & 14.71 \\
\hline
\end{tabular}




$$
\mathrm{C}_{(\mathrm{x}, \mathrm{y}, \mathrm{z})}=\frac{\mathrm{Q}}{2 \pi \overline{\mathrm{u}} \sigma_{\mathrm{y}} \sigma_{\mathrm{z}}} \exp \left(-\frac{\mathrm{y}^{2}}{2 \sigma_{\mathrm{y}}^{2}}\right) \times\left[\exp \left(-\frac{(\mathrm{z}-\mathrm{H})^{2}}{2 \sigma_{\mathrm{z}}^{2}}\right)+\alpha \cdot \exp \left(-\frac{(\mathrm{z}+\mathrm{H})^{2}}{2 \sigma_{\mathrm{z}}^{2}}\right)\right]
$$

onde:

$\mathrm{C}=$ concentração do poluente no ponto de coordenadas $\mathrm{x}, \mathrm{y}, \mathrm{z}\left(\mathrm{g} \cdot \mathrm{m}^{-3}\right)$;

$\mathrm{Q}=$ taxa de emissão do poluente na chaminé $\left(\mathrm{g} . \mathrm{s}^{-1}\right.$ )

$\sigma_{y}=$ coeficiente de dispersão horizontal da concentração da pluma, em função da direção do vento e distancia da fonte $(\mathrm{m})$;

$\sigma_{\mathrm{z}}=$ coeficiente de dispersão vertical da concentração da pluma, em função da direção do vento e distancia da fonte $(\mathrm{m})$; $\left(\mathrm{m} . \mathrm{s}^{-1}\right)$

$\mathrm{v}=$ velocidade média do vento na altura da chaminé

$\mathrm{x}=$ distancia horizontal do emissor ao receptor $(\mathrm{m})$;

$\mathrm{z}=$ altura do receptor ou ponto de medição $(\mathrm{m})$;

$\mathrm{y}=$ distância horizontal do ponto de medição a uma

distancia "y" da linha central da pluma (m);

$\alpha=$ índice de reflexão da pluma ao tocar o solo.

Boçon [10] comenta que as condições para que as equações de pluma gaussiana sejam válidas são bastante idealizadas e raramente ocorrem na natureza. No entanto, devido a sua simplicidade, as equações de pluma gaussiana têm sido amplamente aplicadas, fornecendo resultados que, se não absolutos, ao menos possibilitam estimar os níveis de poluentes a qual a população possa estar exposta.

Para simular o impacto dos TRS emitidos a partir de duas fontes pontuais (caldeira de recuperação e tanque de dissolução) sobre a qualidade do ar na região em estudo foi utilizado o modelo AID (Avaliação Instantânea de Dispersão) desenvolvido por Kawano [3]. A equação básica do modelo é a gaussiana e assume que a concentração média das espécies emitidas de uma fonte pontual obedece a uma distribuição normal gaussiana dos poluentes dentro da pluma, de acordo com a solução proposta por Pasquill. Na solução analítica da equação de difusão, foi assumido que o espalhamento dos poluentes emitidos continuamente da chaminé tem uma distribuição normal ao longo do eixo horizontal da pluma. A estrutura do referido modelo foi desenvolvido em Excel-2000 utilizando a ferramenta Visual Basic.

Os parâmetros meteorológicos utilizados para inicialização do modelo de dispersão AID foram direção e velocidade do vento, pressão atmosférica, temperatura e estabilidade atmosférica. Os parâmetros de entrada correspondentes à fonte emissora consistem de altura da fonte, taxa de emissão de TRS, temperatura e velocidade de saída dos gases, além do diâmetro interno da chaminé. Como dados de saída, considerando todos os dados de entrada (dados meteorológicos, dados da fonte emissora, etc), o modelo gera curvas das isoconcentrações obtidas em função da dispersão do poluente [3]. O mapa com curvas de isoconcentrações pode ser convertido em uma figura digital e sobre esta se pode sobrepor uma planta baixa da região de estudo, com a finalidade de facilitar a avaliação. A Figura 1 mostra a tela com os parâmetros de entrada para inicialização do "software".

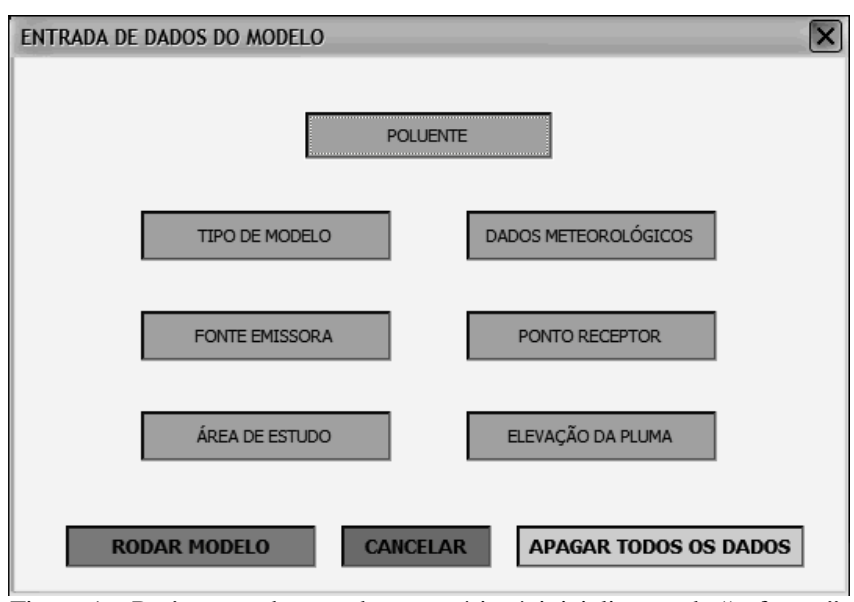

Figura 1 - Parâmetros de entrada necessários à inicialização do "software". [3]

A escolha do modelo AID para este trabalho se deu em função da sua fácil aplicação para verificação de dispersão de poluentes provenientes de fontes fixas.

\section{Descrição da área de estudo}

A fábrica em estudo está localizada no município de Telêmaco Borba no estado do Paraná. O Município localizase na região centro-leste deste estado, possuindo uma área de $1.689,16 \mathrm{~km}^{2}$ e está a $760 \mathrm{~m}$ de altitude [9]. Sua população é estimada em 65.760 habitantes [11]. A Figura 2 apresenta uma imagem aérea da cidade, destacando-se em amarelo a localização da planta industrial da fabricante de papel e celulose, às margens do Rio Tibagi.

\section{Resultados}

$\mathrm{Na}$ simulação para o cálculo da concentração de TRS trabalhou-se, durante o processamento, com dados meteorológicos mais desfavoráveis à sua dispersão, de tal modo que fosse reproduzida a concentração mais elevada. Para tanto, as emissões da caldeira de recuperação e do tanque de dissolução foram assumidas contínuas, durante toda a simulação. A partir dos dados fornecidos pelo programa (isolinhas de concentração, conforme Figura 3), obtiveram-se as concentrações máximas dos poluentes em cada ponto sobre a cidade ou entorno da fábrica (os valores apresentados na figura consideram as duas fontes avaliadas). Para tanto, as diferentes faixas de concentrações de TRS encontradas foram sobrepostas ao mapa da região da fabrica, sendo o resultado apresentado na Figura 3. 


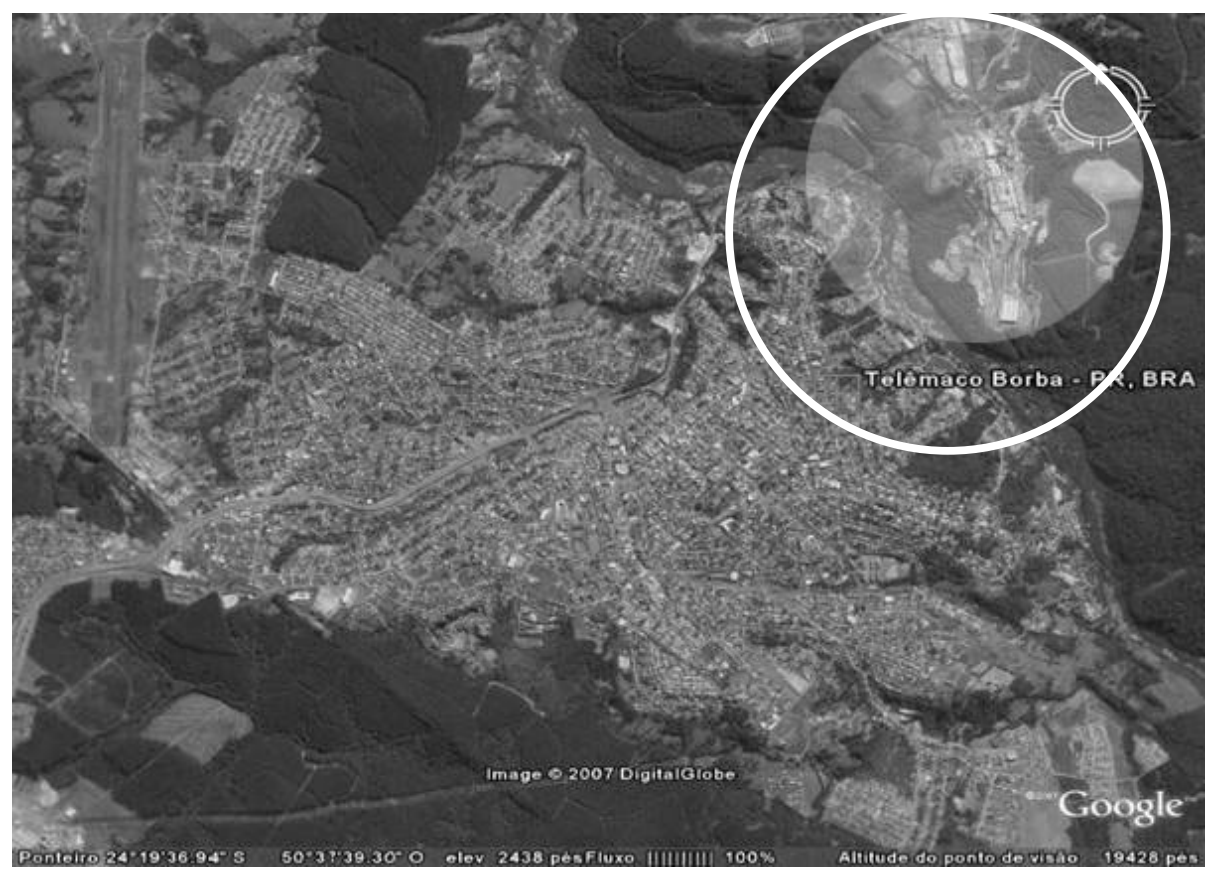

Figura 2 - Imagem aérea da cidade de Telêmaco, destacando a localização da planta industrial.

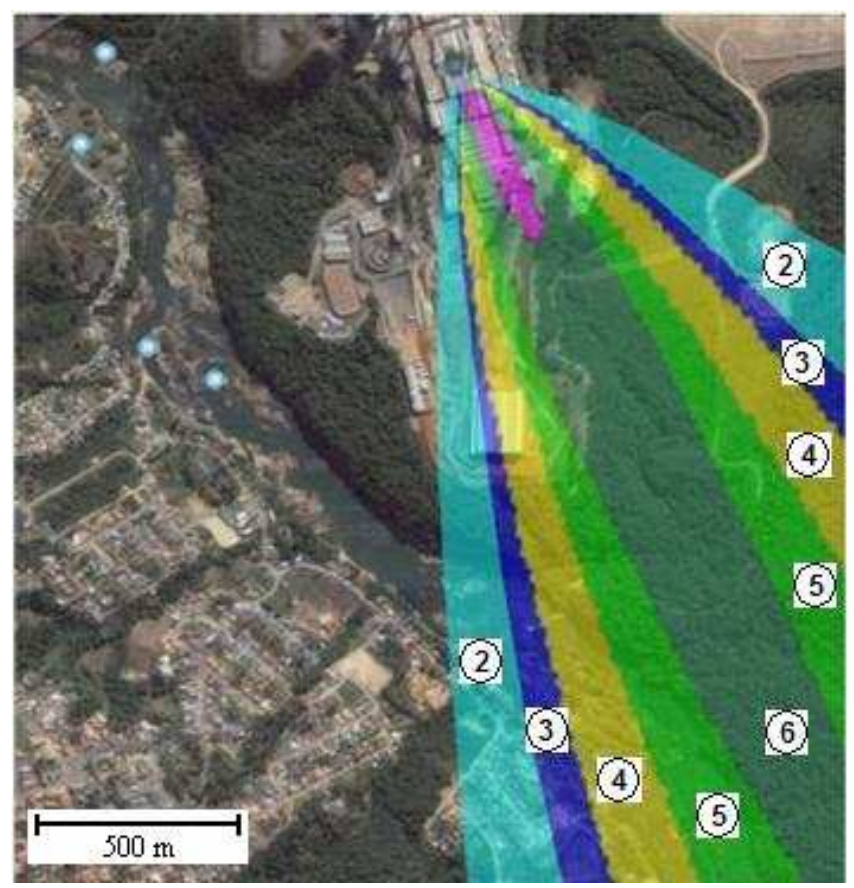

Concentração $\mu \mathrm{g} / \mathrm{m}^{3}$ (média $10 \mathrm{~min}$ )

(1) concentr. $=0$

(2) $0<$ concentr. $<0,000001$

(3) $0,000001 \leqslant$ concentr. $<0,0001$

(4) $0,0001 \leqslant$ concentr. $<0,01$

(5) $0,01 \leqslant$ concentr. $<0,1$

(6) $0,1 \leqslant$ concentr. $<1$

Figura 3 - Curvas de isoconcentrações de TRS representando a sua dispersão

Como era esperado, a máxima concentração estimada de TRS encontrada a partir das emissões das duas fontes deu-se no centro da pluma gerada pelo modelo (isolinha de índice 6 na Figura 3), decrescendo à medida que se afasta do centro. Esta faixa máxima de concentração recaiu dentro dos limites da fábrica, com valor absoluto de $5,94 \mu \mathrm{g} \cdot \mathrm{m}^{-3}$ (3,84 ppb).

Devido à legislação paranaense de qualidade do ar [12] não apresentar parâmetros específicos para compostos reduzidos de enxofre, e também por legislações federais não contemplarem este poluente, adotou-se como referência padrões internacionais. As normas de qualidade do ar do estado norte-americano de Nebraska, por exemplo, adotam, para os TRS, o valor de $100 \mathrm{ppb}$ (média de 30 minutos) como limite máximo de exposição da população no que se refere à percepção odorante [13]. É importante salientar que esse valor refere-se ao limite de percepção olfativo (LPO), a partir do qual o odor é percebido por pelo menos $50 \%$ da 
população a ele exposta $\left(\mathrm{K}_{50}\right)$ [14]. Como os limites de toxicidade quase sempre estão bem acima dos LPO [1,14], é seguro afirmar que, no caso avaliado, a concentração total estimada não apresenta riscos de toxicidade à população exposta, uma vez, pelo valor de concentração obtido, nem ao menos o odor pode ser percebido.

Outros valores de LPO encontrados na literatura são um pouco inferiores ao de Nebraska, como é caso da legislação de algumas províncias do Canadá (Nova Scotia e Ontário), onde o limite de percepção olfativa deste mesmo poluente é de $30 \mathrm{ppb}$ e $31 \mathrm{ppb}$ (média de 1 hora), respectivamente [15].

Verifica-se, dessa forma, que a máxima concentração de TRS obtida por meio da modelagem deste poluente encontra-se abaixo dos limites de percepção odorífera recomendados por órgãos internacionais, como a Nebraska Department of Environmental Quality (Estados Unidos) e a National Pollutant Release Inventory (Canadá). As emissões de TRS para a atmosfera, a partir da caldeira de recuperação e do tanque de dissolução, constituem-se, portanto, em contribuições pequenas para impactar a qualidade do ar na área de influência, conforme ficou demonstrado pelas concentrações obtidas a partir da modelagem.

Convém lembrar que o valor obtido contempla apenas 2 fontes, tomadas como as maiores contribuintes do poluente avaliado. Certamente o somatório de todas as emissões da fábrica, sejam elas a partir de fontes pontuais, fugitivas e evaporativas, resultarão em valores superiores a este.

\section{Conclusões}

O programa AID demonstrou ser capaz de reproduzir o processo de dispersão de poluentes na atmosfera, e desta forma pode ser utilizado como ferramenta para avaliação inicial da dispersão de poluentes provenientes de fontes fixas, aplicável à dispersão de emissões contínuas. A aplicação prática do modelo proposto representa uma forma simples de avaliação do impacto, através das curvas de isoconcentrações, facilitando a visualização e análise dos resultados.

No caso específico desse trabalho, a concentração de 3,84 ppb encontrada para a mistura de TRS considera apenas a emissão devido às duas fontes avaliadas, não contemplando a concentração desses mesmos gases que porventura já existiam na atmosfera avaliada (e que portanto resultariam numa concentração ainda maior). Assim, paralelamente às ferramentas de simulação, é imprescindível o acompanhamento (medição direta com equipamentos) nos pontos de imissão das reais concentrações desses gases, de modo a monitorar o impacto dessas fontes sobre a população a elas exposta.

Apesar da crescente preocupação em relação a esta questão, em nível de Brasil, são poucos os estudos realizados em torno do tema. A maior parte das pesquisas, em Engenharia Sanitária e Ambiental, ainda apóia-se sobre tratamento de resíduos sólidos e líquidos bem como águas de abastecimento. Entretanto, similarmente ao que já vem se observando em âmbito internacional, a expectativa é de que, também no Brasil, ocorra um aumento no controle de fontes industriais, como a adoção de padrões de emissão mais rígidos (específicos para fontes de diferentes naturezas) e a inclusão de um programa de medida e controle/abatimento de odores.

\section{THE ATMOSPHERIC DISPERSION OF ODORANT COMPOUNDS EMITTED FROM PAPER INDUSTRY}

ABSTRACT: The odorant character of total reduced sulfur (TRS) has been generated interest by some of the paper industries in predicting the quality of the air around their issuing sources. This way, the present paper focus on evaluating the impact on the atmosphere resulting from the TRS emissions from a great paper and cellulose manufacturer by the modeling of the gaseous compositions emitted from two points of sources (considered as the largest contributed: boiler of recuperation and dissolution tank). So, it was used the "software" AID (Instantaneous Evaluation of Dispersion) based on Gauss' model for determination of the concentrations (in the air) resultants of those emissions. In that determination, the main meteorological parameters were approached (of the last 3 years) and necessary kinetic of emission to the modeling. The maximum concentration of TRS obtained after the modeling was of 3,84 ppb (added the two evaluated sources), being below the limits of odoriferous perception (LPO) recommended by international organs (Brazil doesn't have specific regulations for this case). As the toxicity limits are almost always above the LPO, it is safe to affirm that, on the evaluated case, the maximum concentration expected doesn't show toxicity risks to the exposed population, once, for the obtained value, neither the odor could be noticed.

Key-words: Atmospheric dispersion; Odor; Paper; Total reduced sulfur; TRS.

\section{REFERÊNCIAS}

[1] SCHIRMER, W. N. Amostragem, análise e proposta de tratamento de compostos orgânicos voláteis (COV) e odorantes em estação de despejos industriais de refinaria de petróleo. 2004. 140f. Dissertação (Pós-graduação em Engenharia Ambiental - Mestrado) - Universidade Federal de Santa Catarina, Florianópolis. 2004.

[2] OLIVEIRA, N. S. Relatório de estágio realizado na klabin papéis monte alegre (Telêmaco Borba-PR). 2006. 44f. Monografia (Graduação em Engenharia Ambiental) - Universidade Estadual do Centro Oeste, Irati. 2006.

[3] KAWANO, M. Desenvolvimento, validação e aplicação de um modelo matemático para dispersão de poluentes atmosféricos. 2003. $121 \mathrm{f}$. Dissertação (Pós-graduação em Engenharia Ambiental - Mestrado) Universidade Federal de Santa Catarina, Florianópolis. 2003.

[4] ALMEIDA, I. T. Poluição atmosférica por material particulado na mineração a céu aberto. 1999. 186f. Dissertação (Pós-graduação em Engenharia de Minas - Mestrado) - Escola Politécnica da Universidade de São Paulo, São Paulo. 1999.

[5] ÁlVARES Jr., O.M.; LACAVA, C.I.V.; FERNANDES, P.S.; Tecnologias e gestão ambiental - Emissões atmosféricas; Serviço Nacional de Aprendizagem Industrial (SENAI); Brasília, 373, 2002. 
[6] TURNER, D. B.; Workbook of atmospheric dispersion estimates, $2^{\text {nd }}$ ed.; Lewis Publishers; New York, 1994.

[7] BRAGA, B. et al. Introdução à engenharia ambiental: o desafio do desenvolvimento sustentável. $2^{\mathrm{a}}$ ed. São Paulo: Pearson Prentice Hall, 2005.

[8] AIR \& WASTE MANAGEMENT ASSOCIATION. Plano de Trabalho para Avaliação de Risco Atmosférico. Seção Brasil. 1997.

[9] SECA - Sistemas de estudos climáticos e ambientais S/C ltda. Documento M-0227-10/10-06/SECA - Relatório de dispersão atmosférica, $51,2002$.

[10] BOÇON, F. T. Modelagem matemática do escoamento e da dispersão de poluentes na microescala atmosférica. 1998. 308f. Tese (Pós-graduação em Engenharia Mecânica - Doutorado) - Universidade Federal de Santa Catarina, Florianópolis. 1998.

[11] IBGE. Contagem da população 2007. Disponível em: http://www.ibge.gov.br/home/estatistica/populacao/contagem2007/PR. pdf. Acesso em 25/11/07.
[12] SEMA - Secretaria de Estado do Meio Ambiente e Recursos Hídricos (Paraná). Resolução 054/2006. Disponível em: www.iap.pr.gov.br/arquivos/File/meioambiente/res_054 06.pdf. Acesso em 14/03/08.

[13] NDEQ - Nebraska Department of Environmental Quality. Nebraska Air Quality. 2002. Disponível em: http://www.deq.state.ne.us. Acesso em: 29/11/07.

[14] CARMO Jr, G. N. R. Otimização e aplicação de metodologias para análises olfatométricas integradas ao saneamento ambiental. 2005. 174f. Tese (Pós-graduação em Engenharia Ambiental - Doutorado) Universidade Federal de Santa Catarina, Florianópolis. 2005.

[15] NPRI - National Pollutant Release Inventory. Report of the national pollutant release inventory multi-stakeholder work group on substances. Ottawa, jul. 2005. Disponível em: www.ec.gc.ca/pdb /npri/documents/WG2005/WG_subtances/WG Report sub e.pdf. Acesso em 29/11/07. 